\title{
A (in)suficiência do regime do direito ao reembolso em Portugal: o estudo particular das cooperativas vitivinícolas da região demarcada do Douro
}

The (in)sufficiency of the right to reimbursement in Portugal.

The particular study of wine cooperatives in the Douro demarcated region

\author{
Deolinda A. Meira' \\ Ana Maria Bandeira² \\ Vítor Gonçalo 3 \\ Instituto Politécnico do Porto/ISCAP/CECEJ (Portugal)
}

Sumário: 1. Introdução. 2. A problemática da qualificação jurídica versus a qualificação contabilística do capital social cooperativo. 3. A alteração do regime jurídico do direito ao reembolso como possível solução. 4. A reforma do regime do direito ao reembolso. 5. 0 parecer da Comissão de Normalização Contabilística. 6. A necessidade de um outro enquadramento contabilístico para as cooperativas. 7. Evidência empírica: o caso das cooperativas da Região Demarcada do Douro. 8. Conclusões. 9. Bibliografia.

Contents: 1. Introduction. 2. The problem of legal qualification versus the accounting qualification of cooperative share capital. 3. The amendment of the legal regime of the right to reimbursement as a possible solution. 4 . The reform of the regime of the right to reimbursement. 5. The opinion of the Standards Committee Accounting 6.

1 Professora Adjunta do Instituto Politécnico do Porto / ISCAP / CECEJ. Correio eletrónico: meira@iscap.ipp.pt. Correio postal: Instituto Superior de Contabilidade e Administração do Porto, Rua de Jaime Lopes de Amorim, 4465-004 S. Mamede de Infesta, PORTUGAL.

2 Professora Adjunta do Instituto Politécnico do Porto / ISCAP / CECEJ / CEPESE. Correio eletrónico: meira@iscap.ipp.pt. Correio postal: Instituto Superior de Contabilidade e Administração do Porto, Rua de Jaime Lopes de Amorim, 4465-004 S. Mamede de Infesta, PORTUGAL.

3 Mestre em Contabilidade e Finanças pelo do Instituto Politécnico do Porto / ISCAP. Contabilista Certificado. Correio eletrónico: vitormvgoncalo@gmail.com. Correio postal: Instituto Superior de Contabilidade e Administração do Porto, Rua de Jaime Lopes de Amorim, 4465-004 S. Mamede de Infesta, PORTUGAL. 
The need for a new accounting treatment for cooperatives. 7. Empirical evidence: the case of cooperatives in the Douro Region. 8. Conclusions. 9. Bibliography.

Resumo: O presente estudo pretende demonstrar que as alterações introduzidas no regime jurídico do direito ao reembolso, na reforma do Código Cooperativo português de 2015, não são suficientes para afastar a qualificação contabilística do capital social cooperativo como um passivo financeiro. Esta qualificação decorre da sujeição das cooperativas às normas internacionais de contabilidade, com particular destaque para a IAS 32. A relevância prática desta questão é demonstrada por um estudo empírico que analisa os efeitos que a aplicação do atual enquadramento contabilístico tem nas cooperativas vitivinícolas da Região Demarcada do Douro. Conclui-se defendendo uma intervenção legislativa que permita a sujeição das cooperativas a um tratamento contabilístico específico e diferenciado, e que respeite a caraterística da variabilidade do capital social, decorrente do direito ao reembolso das entradas em caso de demissão do cooperador, ao abrigo do princípio cooperativo da adesão voluntária e livre.

Palavras-chave: cooperativa, direito de reembolso, direito de demissão, IAS32, capital social, passivo financeiro.

Abstract: This study intends to demonstrate that the changes introduced in the legal regime of the right to reimbursement, in the Portuguese Cooperative Code reform of 2015, are not sufficient to remove the accounting qualification of cooperative share capital as a debt. This qualification stems from the subjection of cooperatives to international accounting standards, with particular reference to IAS 32. The practical relevance of this issue is demonstrated by an empirical study that analyses the effects that the application of the current accounting treatment for cooperatives has on wine cooperatives in the Douro Demarcated Region. It concludes by advocating a legislative intervention that allows the cooperatives to be subject to a specific and differentiated accounting treatment, respecting the variability of share capital, resulting from the right to reimbursement of contributions in case of withdraw of the cooperator, under the cooperative principle of voluntary and open membership.

Keywords: cooperative, right to reimbursement, right to withdraw, IAS32, share capital, debt. 


\section{Introdução}

O presente estudo tem em vista refletir sobre o regime jurídico do direito ao reembolso no ordenamento português e avaliar da sua suficiência para impedir a classificação contabilística do capital social cooperativo como um passivo financeiro.

No ordenamento português não existe um tratamento contabilístico específico e diferenciado para as cooperativas face às sociedades comerciais, pelo que estas estão sujeitas às normas internacionais de contabilidade, designadamente à IAS 32, com o risco de o capital social ser qualificado, contabilisticamente, como um recurso alheio e não como um recurso próprio, porque reembolsável em caso de demissão do cooperador, ao abrigo do princípio cooperativo da adesão voluntária e livre.

Dado que a legislação cooperativa portuguesa sofreu uma profunda reforma em 2015, com a entrada em vigor da Lei n. ${ }^{\circ}$ 119/2015, de 31 de agosto, que aprovou um novo Código Cooperativo $(\text { CCoop })^{4}$, pretende-se, em concreto, aferir se as alterações introduzidas, quanto ao regime do direito ao reembolso, permitem afastar a qualificação contabilística do capital social cooperativo como um passivo financeiro, tendo em conta as orientações constantes da «IFRIC 2 - Ações dos membros em entidades cooperativas e instrumentos semelhantes» ${ }^{5}$, que é uma interpretação emitida pelo International Accountig Standards Board (IASB), na decorrência das fortes pressões exercidas pelo movimento cooperativo junto daquele organismo e junto da União Europeia, perante a desadequação da aplicação das normas internacionais de contabilidade, designadamente da IAS 32, às cooperativas.

Para demonstrar a relevância prática desta questão, recorreu-se a um estudo empírico com vista a analisar os efeitos económico-financeiros que a aplicação do atual regime contabilístico - assente nas

${ }^{4}$ A primeira lei cooperativa portuguesa foi a Lei Basilar do Cooperativismo (Lei de 2 de julho de 1867). Em 1888, as cooperativas passaram a ser regidas pelo Código Comercial de Veiga Beirão. Em 1980, entrou em vigor um Código Cooperativo (Decreto-Lei n. ${ }^{\circ}$ 454/80, de 9 de outubro). Em 1997, entrou em vigor um novo Código (Lei n. ${ }^{\circ}$ 51/96), que foi, entretanto, alterado: pelo Decreto-Lei n. ${ }^{\circ} 343 / 98$, de 6 de novembro; pelo Decreto-Lei n. ${ }^{\circ}$ 131/99, de 21 de abril; pelo Decreto-Lei n. ${ }^{\circ}$ 108/2001, de 6 de abril; pelo Decreto-Lei n. ${ }^{\circ}$ 204/2004, de 19 de agosto; e pelo Decreto-Lei n. ${ }^{\circ}$ 76-A/2006, de 29 de março. Em 30 de setembro de 2015, entrou em vigor o atual Código Cooperativo (CCOop).

5 A mencionada interpretação consta do Regulamento (CE) n. ${ }^{\circ}$ 1073/2005 da Comissão (o texto pode ler-se em http://eur-lex.europa.eu/samartapi/cgi). 
normas internacionais de contabilidade, com particular destaque para a IAS 32 - tem nas cooperativas vitivinícolas da Região Demarcada do Douro (RDD). Para tal, procedeu-se ao cálculo dos principais rácios de endividamento e liquidez das cooperativas daquela região, antes e após a aplicação da IAS 32, e validaram-se os resultados obtidos com recurso a método estatístico.

\section{A problemática da qualificação jurídica versus a qualificação contabilistica do capital social cooperativo}

O problema de fundo de que partimos é a questão da qualificação do capital social cooperativo.

Efetivamente, na decorrência da entrada em vigor, em 1 de janeiro de 2010, do Sistema de Normalização Contabilistica (SNC)6, que é de aplicação obrigatória às cooperativas (al. e) do n. 1 do art. $3 .^{\circ}$ do SNC), estas viram-se confrontadas com a inevitabilidade de o seu capital social ser qualificado, contabilisticamente, como um recurso alheio (passivo financeiro) e não como um recurso próprio, uma vez que a Norma Contabilística de Relato Financeiro $n .^{\circ} 27$ (NCRF 27), no seu $\S 10 .^{\circ}$, que corresponde à $I A S 32^{7}$, dispôs que um instrumento financeiro, qualquer que seja a sua forma, se puder ser reembolsado a pedido do subscritor, será classificado como um passivo financeiro ${ }^{8}$.

Tal determinará, então, no caso da cooperativa, e por força do que dispõe o art. $24 .^{\circ}$ do CCoop, que o capital social seja qualificado contabilisticamente, como passivo.

De facto, os cooperadores têm um verdadeiro direito de saída ou direito de demissão, tal como resulta do n. ${ }^{\circ} 1$ do art. $24 .^{\circ}$ do CCoop ${ }^{9}$.

6 Aprovado pelo Decreto-Lei n. ${ }^{\circ}$ 158/2009, de 13 de julho.

7 A International Accounting Standard 32 (IAS 32) aplica-se a todas as empresas europeias em consequência do processo de harmonização contabilística internacional a que assistimos na última década e que se iniciou com a promulgação do Regulamento 1606/2002 da União Europeia, pelo qual se adotaram formalmente as Normas Internacionais de Contabilidade. V., por todos, Ana Maria Rodrigues (Coord.), SNCSistema de Normalização Contabilistica (Coimbra: Almedina, 2016, 3. a edição, 2016), passim.

8 V., sobre esta questão, Jean-Claude Detilleux e Caroline Naett, «Les Cooperatives face aux Normes Comptables Internationales: Le cas de I' IAS 32», RECMA - Revue Internationale de L'Économie Sociale, n. ${ }^{\circ} 295$ (2005): 7-19.

$9 \mathrm{O}$ n. 1 do art. $24 .^{\circ}$ do CCoop estabelece que "Os cooperadores podem solicitar a sua demissão nas condições estabelecidas nos estatutos ou, no caso de estes serem omissos, no fim de um exercício social, com pré-aviso de 30 dias, sem prejuízo da responsabilidade pelo cumprimento das suas obrigações como membros da cooperativa». 
Ora, esta saída do cooperador da cooperativa tem como consequência o reembolso da sua entrada de capital, uma vez que o n. ${ }^{\circ} 1$ do art. 89. ${ }^{\circ}$ do CCoop dispõe que "em caso de reembolso dos títulos de capital, o cooperador que se demitir tem direito ao montante dos títulos de capital realizados segundo o seu valor nominal, no prazo estabelecido pelos estatutos ou, supletivamente, no prazo máximo de um ano».

Este direito de reembolso das entradas, que é uma manifestação do Princípio da adesão voluntária e livre (art. 3. ${ }^{\circ}$ do CCoop), confere à cooperativa uma variabilidade estrutural, quer no plano dos cooperadores quer no plano do capital social $\left(n .{ }^{\circ} 1\right.$ do art. $2 .^{\circ}$ e n. ${ }^{\circ} 1$ do art. $811^{\circ}$, ambos do CCoop). A cifra do capital dependerá do número de membros (uma vez que a dita cifra resulta da soma das entradas dos cooperadores) e sendo variável o número de cooperadores também o será o capital.

Juridicamente, e não obstante o seu caráter variável, entendemos que o capital social da cooperativa deverá ser sempre considerado como um recurso próprio ${ }^{10}$, ainda que, como afirma Pastor Sempere, "de menor qualidade» ${ }^{11}$, já que não é uma fonte estável de financiamento para a cooperativa.

Dois argumentos principais poderão ser aduzidos a favor desta nossa posição.

Um primeiro argumento resulta do facto de as entradas para o capital social fazerem parte do aspeto obrigacional da posição jurídica do cooperador, realizando-se no âmbito do próprio contrato social, tendo uma causa distinta da do contrato de empréstimo ${ }^{12}$. De facto, o cooperador só adquire a qualidade de membro mediante a realização de uma entrada para o capital social ${ }^{13}$, entrada que não poderá ser inferior a três títulos de capital (art. 83. ${ }^{\circ}$ do CCoop).

10 No mesmo sentido, María del Carmen Pastor Sempere, Los recursos propios en las sociedades cooperativas (Madrid: Editoriales de Derecho Reunidas, SA, 2002), 64 e ss.; Francisco Vicent Chuliá, Ley General de Cooperativas, Tomo XX, Vol. 3. ${ }^{\circ}$ (Madrid: Editoriales de Derecho Reunidas, SA, 1994), 210 e ss.; Isabel-Gemma Fajardo García, "La masa activa y pasiva en el concurso de Cooperativas», in: Estudios sobre la Ley Concursal. Libro Homenaje a Manuel Olivencia, Tomo V (Madrid-Barcelona, 2005): 5244.

11 María del Carmen Pastor Sempere, Los recursos propios en las sociedades cooperativas..., 64 .

12 Neste sentido, v. Carlos Vargas Vasserot, "La NIC 32 y el capital social cooperativo», REVESCO. Revista de Estudios Cooperativos, n. 91 (2007): 114.

13 O capital social é representado por títulos de capital, que são nominativos e que têm um valor nominal de cinco euros ou um seu múltiplo (art. 82. ${ }^{\circ}$ do CCoop). 
A entrada para o capital social é, assim, uma condição necessária, ainda que não suficiente para a aquisição da qualidade de cooperador ${ }^{14}$. A cooperativa tem, a título principal, um escopo mutualístico e, por isso, para desenvolver o seu projeto empresarial, necessita - para além das entradas para o capital social - da participação dos cooperadores na atividade que constitui o seu objeto social. De facto, da definição de cooperativa constante do art. $2{ }^{\circ}$ do CCoop, resulta a absoluta instrumentalidade da cooperativa face aos seus membros. Tal significa que a cooperativa é um instrumento de satisfação das necessidades individuais dos cooperadores que no seio dela, e através dela, cooperam, não existindo um escopo autónomo da cooperativa face aos interesses dos cooperadores. Por isso, nas cooperativas, constitui requisito sine qua non, para além da realização das entradas de capital, o envolvimento direto e ativo dos seus membros na própria atividade que a cooperativa desenvolve [al. c) do n. ${ }^{\circ} 2$ do art. $22 .{ }^{\circ}$ do CCoop], ou seja, no cumprimento do seu objeto social.

Um segundo argumento resulta do facto de os cooperadores, quando se demitem, não terem direito à restituição da sua entrada, mas à sua liquidação ${ }^{15}$. Como acertadamente escreveu Vicent Chuliá, as entradas para o capital social "são objeto de liquidação e não de restituição ou reembolso, em sentido próprio, tal como num empréstimo ${ }^{16}$. Efetivamente, o cooperador quando se demite da cooperativa dificilmente receberá de volta aquilo que entregou àquela, a título de entrada. Poderá receber mais ou menos, dependendo da situação líquida da cooperativa, podendo até e no limite perder todo o seu investimento, situação que não tem semelhança com o reembolso de um empréstimo. Entendemos, por isso, que o mais correto será o termo liquidação e não reembolso, já que ao cooperador não se reconhece o direito a recuperar exatamente aquilo com que entrou para a cooperativa. O capital que o cooperador traz para a cooperativa será um capital de risco, representando, nas palavras de Vicent Chuliá, valores patrimoniais "comprometidos nos riscos da empresa» ${ }^{17} \mathrm{e}$, por isso,

14 Neste sentido, v. Deolinda A. Meira, O regime económico das cooperativas no Direito Português: o capital social (Porto: Vida Económica, 2009), 212-220.

15 Neste sentido, v. Study Group on European Cooperative Law (SGECOL), Draft Principles of European Cooperative Law (draft PECOL), May 2015, http://www.euricse.eu/wp-content/uploads/2015/04/PECOL-May-2015.pdf (última consulta em 20 de novembro de 2016).

16 Francisco Vicent Chuliá, Ley General de Cooperativas..., 185.

17 Francisco Vicent Chuliá, Ley General de Cooperativas..., 211. No mesmo sentido, Manuel Paniagua Zurera, Las Sociedades Cooperativas. Las Sociedades Mutuas de Seguros y las Mutualidades de Previsión Social (Madrid-Barcelona: Marcial Pons, 2005), 247 e 262-266. 
poderá perder, por completo, tais valores. Daí que não se possa afirmar que o cooperador que se demite tem direito à restituição sem mais da sua entrada, mas apenas a que Ihe liquidem a sua entrada para o capital social, a qual pode ter sofrido um aumento ou uma redução.

Este entendimento é confirmado pelo legislador cooperativo português, quando, no n. ${ }^{\circ} 2$ do art. $89 .^{\circ}$ do CCoop, consagra que o valor nominal dos títulos de capital realizados que deverão ser restituídos ao cooperador que se demitir «será acrescido dos juros a que tiver direito relativamente ao último exercício social, da quota-parte dos excedentes e reservas não obrigatórias repartíveis, e deduzido, se for o caso, das perdas que the sejam imputáveis reveladas no balanço do exercício no decurso do qual surgiu o direito ao reembolso». Desta norma resulta então que, só por mera coincidência, o cooperador receberá o montante com que entrou para a cooperativa.

Contabilisticamente, a questão da qualificação do capital social cooperativo é mais complexa.

O SNC foi pensado, sobretudo, para sociedades capitalistas convencionais $^{18}$, não tendo, por isso, em conta as especificidades das cooperativas, designadamente o carácter variável do seu capital social, decorrente do direito de reembolso das entradas, em caso de demissão do cooperador $^{19}$. Assim, e tal como já foi referido, o § $10^{\circ} \mathrm{d}$ a NCRF 27 dispõe que um instrumento financeiro, qualquer que seja a sua forma, se puder ser reembolsado a pedido do subscritor, será considerado como um passivo financeiro.

Este alheamento das especificidades da cooperativa tem, então, como consequência, do ponto de vista contabilístico, a classificação do capital social cooperativo como passivo, com as implicações

18 Nos termos do n. ${ }^{\circ} 1$ do art. 3. ${ }^{\circ}$ do Decreto-Lei n. ${ }^{\circ}$ 158/2009, de 13 de julho, o SNC é obrigatoriamente aplicável às seguintes entidades: sociedades abrangidas pelo Código das Sociedades Comerciais, empresas individuais reguladas pelo Código Comercial, estabelecimentos individuais de responsabilidade limitada, empresas públicas, cooperativas, agrupamentos complementares de empresas e agrupamentos europeus de interesse económico.

19 Sobre a desadequação das Normas Internacionais de Contabilidade face às cooperativas, v. Belén Fernández Feijoo Souto e María José Cabaleiro Casal, «Clasificación del capital social de la cooperativa: una visión crítica», CIRIEC-España, Revista de Economía Pública Social y Cooperativa, n. ${ }^{\circ} 58$ (2007): 7-29; Deolinda A. Meira e Ana Maria Bandeira, "A IAS 32 e os novos critérios de contabilização das entradas para o capital social das cooperativas. Uma análise contabilística e jurídica», Revista de Ciências Empresariais e Jurídicas, n. ${ }^{\circ} 16$ (2010): 145-164; Ana Maria Gomes Rodrigues, «Os novos desafios da Contabilidade para Organizações da Economia Social que aplicam o SNC - As Cooperativas», Revista Cooperativismo e Economia Social, n. 32 (20092010): 115-140. 
económico-financeiras daí resultantes, a saber: o agravamento do problema endémico das cooperativas que é o da sua subcapitalização; a consideração das entradas dos cooperadores como dívidas aumentará o endividamento e a deterioração da sua solvência; dificuldades na obtenção de financiamento externo, uma vez que as entidades financeiras concedem o crédito em função, entre outros, dos recursos próprios da entidade; aumento do risco de insolvência, dado que ao aumentar o endividamento, pelo incremento do passivo e redução do ativo, acentua-se o risco de insolvência da cooperativa; muitas das ajudas e subsídios que são concedidos às cooperativas exigem determinadas relações entre recursos próprios e alheios, o mesmo acontecendo com os empréstimos concedidos por instituições de crédito.

\section{A alteração do regime jurídico do direlto ao reembolso como Possível solução}

Um caminho possível para a solução do problema da qualificação contabilística do capital social cooperativo passaria pela introdução de ajustamentos no regime jurídico do direito ao reembolso, seguindo as orientações constantes da «IFRIC 2 - Ações dos membros em entidades cooperativas e instrumentos semelhantes», acima mencionada ${ }^{20}$.

Nos termos da «IFRIC 2», e de um modo sucinto, o direito contratual do titular de um instrumento financeiro de pedir a remissão não implicará, por si só, que esse instrumento financeiro seja classificado como passivo financeiro, devendo a entidade ter em conta todos os termos e condições do instrumento financeiro para determinar a sua classificação como passivo ou capital próprio. Tais termos e condições constarão das leis, regulamentos e estatutos aplicáveis à entidade e que se encontrem em vigor à data da classificação.

Assim, esta Interpretação do IASB dispõe que as ações dos membros (leia-se entradas de capital) poderiam ainda ser classificadas como capital próprio, se ocorresse qualquer das seguintes condições:

- a entidade emitente tivesse um direito incondicional de recusar a remissão das ações dos membros;

20 Sobre estas exigências, v. Lorea Andicoechea e Miguel A. Zubiaurre, «Equity-Liability Accounting Debate in Worker Co-operative Entities Members' Shares», Journal of Co-Operative Accounting and Reporting, n. ${ }^{\circ}$ V1 (2012): 28-46; Francisco José Torres Pérez, Régimen Jurídico de las Aportaciones Sociales en la Sociedad Cooperativa (Navarra: Editorial Thomson Aranzadi, 2006): 454 e ss. 
- a lei, os regulamentos e os estatutos que governam a entidade pudessem impor vários tipos de proibições à remissão das ações dos membros, como por exemplo, proibições incondicionais ou proibições baseadas em critérios de liquidez.

Dispõe-se, igualmente, que se a remissão for incondicionalmente proibida por lei local, regulamento ou estatutos da entidade, as ações dos seus membros serão classificadas como capital próprio.

Mas admite-se para além da proibição incondicional absoluta, no sentido em que todas as remissões serão proibidas, a proibição incondicional parcial, no sentido em que só se proíbe a remissão de ações dos membros se essa remissão implicar que o montante do capital realizado desça abaixo de um nível especificado nos estatutos.

Assim, à luz da «IFRIC 2 », e tendo por referência a cooperativa, as partes sociais desta só poderão ser consideradas como capital (entenda-se capital próprio), desde que a cooperativa tenha um direito incondicional de recusar o reembolso da parte social do cooperador e os estatutos ou a legislação definam um limite a partir do qual o capital social não poderá ser reduzido em caso de reembolso.

Tal interpretação, que assenta na ideia da necessidade de conferir maior estabilidade ao capital social cooperativo, remete-nos para a possibilidade de introduzir limites e até de excluir o direito ao reembolso; e, em consequência, o estabelecimento de um adequado regime jurídico de proteção do capital social mínimo.

Vejamos se o legislador, na reforma, foi sensível a estas exigências.

\section{A reforma do regime do direito ao reembolso}

No novo Código Cooperativo, o legislador continua a reconhecer expressamente a variabilidade do capital social como uma caraterística essencial da identidade cooperativa.

No entanto, o legislador alargou a possibilidade do estabelecimento de limites ao exercício do direito ao reembolso, de modo a conferir maior estabilidade ao capital social cooperativo. Aos mecanismos já previstos no Código Cooperativo de 1996 - «a possibilidade de diferir o reembolso durante um certo período de tempo» ( . $^{\circ} 1$ do art. $89 .^{\circ}$ do CCoop); "a possibilidade de estabelecer deduções ao direito ao reembolso» ( $\mathrm{n}{ }^{\circ} 2$ do art. 89..$^{\circ}$ do CCoop); "O estabelecimento de prazos mínimos de permanência e de regras que condicionem a saída a um aviso prévio» (n.os 2 e 3 do art. 24. ${ }^{\circ}$ do CCoop); "o regime de responsabilidade externa dos cooperadores» (art. $23 .^{\circ}$ e $800^{\circ}$ do CCoop); a «fixação 
de um capital social mínimo» (n. ${ }^{\circ} 2$ do art. $81 .^{\circ}$ do CCoop); acrescenta-se no novo Código a possibilidade de os estatutos poderem prever a suspensão do reembolso (n.os 3 e 4 do art. $89 .{ }^{\circ}$ do CCoop).

Centremo-nos nesta nova possibilidade.

A regra geral no ordenamento português continua a ser a de que não é possível constituir uma cooperativa sem capital social, devendo este estar necessariamente determinado nos estatutos da cooperativa (art. 16. ${ }^{\circ}$, n. ${ }^{\circ} 1$, al. f) do CCoop). Este capital social deverá ser, no mínimo, de 1500 euros (n. 2 do art. 81. ${ }^{\circ}$ do CCoop), podendo a legislação complementar que regula cada um dos ramos fixar um mínimo diferente ${ }^{21}$.

O Código Cooperativo de 1996 não consagrava a impossibilidade de o reembolso das entradas afetar o capital social mínimo. Inspirado no Estatuto da Sociedade Cooperativa Europeia (ESCE) que estabeleceu que o prazo durante o qual os sócios terão direito ao reembolso das suas entradas, quando deixam de fazer parte da cooperativa, será suspenso, enquanto esse reembolso implicar a redução do capital subscrito para um montante inferior ao capital social mínimo ( $n .^{\circ} 4$ do art. $3 .^{\circ}$ do ESCE) - o legislador consagra agora, no n. ${ }^{\circ} 3$ do art. $89 .^{\circ}$ do CCoop, que uos estatutos podem prever que, quando num exercício económico o montante dos títulos de capital a reembolsar supere uma determinada percentagem do montante do capital social que neles se estabeleça. Assim, se essa percentagem for, por exemplo, de $20 \%$, tal significa que $80 \%$ do capital social deverá ser contabilizado como recurso próprio e $20 \%$ como passivo.

Deste modo, e na linha das disposições constantes da «IFRIC 2», acima mencionada, parece consagrar-se uma proibição incondicional parcial, no sentido em que se proíbe a remissão de títulos de capital dos membros cooperadores que se demitem se essa remissão implicar que o montante do capital realizado desça abaixo de um nível especificado nos estatutos.

Convém, no entanto, ter presente que o novo Código Cooperativo obriga a que a decisão de suspensão do reembolso seja fundamentada e sujeita-a a ratificação da assembleia geral (n. ${ }^{\circ} 4$ do art. $89 .^{\circ}$ do CСоop). Estes condicionalismos pretendem assegurar que as limitações ao exercício do direito ao reembolso se fundam em razões objetivas, excluindo-se qualquer restrição que radique no mero arbítrio dos diri-

21 V. Deolinda A. Meira, "Contributos legislativos para a criação de empresas cooperativas: a livre fixação do capital social», CIRIEC-España, Revista Jurídica de Economía Social y Cooperativa, n. ${ }^{\circ} 26$ (2015): 35-37. 
gentes da cooperativa ou num excesso de valorização relativa dos interesses da cooperativa e, ainda, que tais limitações não ultrapassem um nível, razoável e justo, de proteção da solvência financeira da cooperativa. Ora, estes condicionalismos têm como consequência que a proibição parcial deixe de ser incondicional, não respeitando, deste modo, as exigências constantes da «IFRIC $2 »^{22}$.

Quanto à proibição incondicional absoluta de que fala a «IFRIC 2» para impedir a classificação do capital social como passivo, a mesma foi rejeitada pelo legislador na reforma do Código Cooperativo, não se acolhendo a solução adotada no ordenamento espanhol que admite a possibilidade de, mediante cláusula estatuária, se introduzir uma dualidade no capital social das cooperativas, que passa a estar representado por entradas reembolsáveis ou por entradas cujo reembolso possa ser recusado incondicionalmente pelo órgão de administração da cooperativa em caso de demissão do cooperador ${ }^{23}$.

O novo Código Cooperativo mantém a proibição da supressão do direito de demissão ( $n .^{\circ} 3$ do art. $24 .^{\circ}$ do CCoop), permitindo-se apenas que os estatutos limitem tal direito «estabelecendo regras e condições para o seu exercício».

\section{O parecer da Comissão de Normalização Contabilística}

Na base desta opção legislativa, que é inquestionavelmente a que melhor preserva a identidade cooperativa, respeitando o princípio cooperativo da adesão voluntária e livre, estará, desde logo, a circunstância de, em Portugal, a Comissão de Normalização Contabilística (CNC), que tem como missão, no domínio contabilístico, entre outras competências, a de emitir pareceres relativos ao conjunto das entidades inseridas no setor empresarial e setor público, de modo a estabelecer e assegurar procedimentos contabilísticos harmonizados com as normas europeias e internacionais da mesma natureza, ter proferido um parecer nos termos do qual o capital social cooperativo deverá ser classificado contabilisticamente como um recurso próprio.

22 V., neste sentido, Isabel-Gemma Fajardo García «La reforma del Código Cooperativo Portugués desde una perspectiva de Derecho Comparado», Revista de Ciências Empresariais e Jurídicas, n. ${ }^{\circ} 27$ (2016): 62-63.

${ }^{23}$ V., sobre esta questão, Carlos Vargas Vasserot, "Aportaciones exigibles o no exigibles: ésa es la cuestión», CIRIEC-España, Revista Jurídica de Economía Social y Cooperativa,.$^{\circ} 22$ (2011): 75-119; Rodrigo Viguera Revuelta, El derecho de reembolso en las sociedades cooperativas (Valencia: Tirant Lo Blanch, 2015), 339 e ss. 
Este parecer foi emitido em 15 de março de 2012, na sequência de um pedido dirigido à CNC pela Cooperativa António Sérgio para a Economia Social (CASES), que é uma cooperativa de interesse público que congrega o Estado e diversas organizações da economia SOCial24.

A CASES assume-se como uma peça central de um sistema de relações entre o Estado e as cooperativas, prestando a estas últimas apoio técnico nos domínios legal, fiscal e financeiro.

No referido parecer, que vai de encontro ao entendimento acima exposto quanto à classificação jurídica do capital social cooperativo, diz-se que "as entradas de capital dos cooperantes não se enquadram no § 10 da NCRF 27, enquanto o cooperante não manifestar a vontade de se demitir (...). Em conclusão, é entendimento da Comissão de Normalização Contabilística que as entradas dos cooperantes devem ser consideradas como instrumentos de capital próprio. Serão reconhecíveis como passivo (por contrapartida de capital próprio) as quantias que o participante tenha direito a receber por via da sua demissão. Sendo assim, e em conformidade com esta interpretação da Comissão de Normalização Contabilística, deverão as cooperativas classificar contabilisticamente o seu capital social como um recurso próprio» ${ }^{25}$.

Note-se que, tal como é destacado no site da CNC, estes pareceres têm um carácter meramente informativo, não constituindo, em caso algum, um ato administrativo, e devem ser apreciados tendo em conta a data em que foram produzidos. Assim, este parecer da CNC, ainda que importante, não se afigura suficiente para a resolução do problema da qualificação contabilística do capital social cooperativo.

24 A CASES foi criada pelo Decreto-Lei n. ${ }^{\circ} 282 / 2009$, de 7 de outubro. O regime jurídico das cooperativas de interesse público (ou régies cooperativas) consta de um diploma próprio, o Decreto-Lei n. ${ }^{\circ} 31 / 84$, de 21 de janeiro. O n. ${ }^{\circ} 1$ do art. $1 .^{\circ}$ deste diploma define as cooperativas de interesse público como pessoas coletivas, nas quais, para a prossecução dos seus fins, se associam o Estado ou outras pessoas coletivas de direito público e cooperativas ou utentes dos bens e serviços produzidos ou pessoas coletivas de direito privado, sem fins lucrativos. Sobre as especificidades das cooperativas de interesse público, v. João Leite, J., Cooperativas de interesse de público em Portugal, texto disponível em http://www.cases.pt/0_content/actividades/doutrina/ cooperativas_de_interesse_publico_em_portugal.pdf (última consulta em 20 de novembro de 2016).

25 V. http://www.cnc.min-financas.pt/_siteantigo/0_new_site/FAQs/sitecnc_faqs. htm\#P25 (consulta efetuada em 21 de novembro de 2016). 


\section{A necessidade de um outro enquadramento contabilístico para as cooperativas}

Em nome da certeza e da segurança jurídicas, impõe-se uma intervenção legislativa que permita a sujeição das cooperativas a um tratamento contabilístico específico e diferenciado.

Deste modo, advogamos o afastamento da aplicação do SNC às cooperativas, devendo estas ser abrangidas pelo normativo contabilístico aplicável às entidades sem fins lucrativos.

Em Portugal existem normas contabilísticas específicas para as «entidades sem fins lucrativos» (ESNL) constantes do Decreto-Lei n. ${ }^{\circ} 36$ A/2011, de 9 de março. Contudo, o n. ${ }^{\circ} 2$ do art. $5 .^{\circ}$ deste diploma excluiu expressamente as cooperativas da aplicação deste regime (com a exceção das cooperativas, "cujo ramo específico não permita sob qualquer forma, direta ou indireta, a distribuição de excedentes, designadamente as cooperativas de solidariedade social»).

O facto de o legislador prever que somente as cooperativas que não podem, direta ou indiretamente, distribuir excedentes ficarão sujeitas ao regime contabilístico das ESNL demonstra o desconhecimento por parte dele das especificidades do regime jurídico das cooperativas, designadamente que estas não têm um escopo lucrativo nem distribuem ganhos económicos ou financeiros diretos aos respetivos membros.

A possibilidade de a cooperativa fazer retornar uma parte dos excedentes aos seus membros não põe em causa a sua natureza de entidade sem fim lucrativo, pois a distribuição de excedentes não configura uma distribuição de dividendos. Efetivamente, o art. $2 .^{\circ}$ do cCoop consagra o escopo não lucrativo das cooperativas, uma vez que, a título principal, a cooperativa visa "sem fins lucrativos, a satisfação das necessidades e aspirações económicas, sociais ou culturais» dos seus membros, que são os destinatários principais das atividades económicas e sociais que esta leva a cabo. É o chamado escopo mutualístico das cooperativas, sendo este escopo que permite distinguir claramente as cooperativas das entidades lucrativas, designadamente das sociedades comerciais (que não cumprem as aspirações próprias das cooperativas).

As cooperativas são formadas por pessoas que querem cooperar entre si ou, mais especificamente, querem vender conjuntamente, trabalhar conjuntamente, consumir conjuntamente. Para cumprir este propósito, constituem uma pessoa coletiva (a cooperativa) no âmbito da qual trabalham, consomem e vendem. Tal como escreveu Cunha Gonçalves, as cooperativas procuram «libertar os operá- 
rios do regime do salariado, da exploração capitalista, eliminando o patrão, visto que os trabalhadores, associando-se e produzindo em comum, se apropriavam do lucro da produção, sendo patrões de si próprios; e, eliminando o comerciante, o banqueiro, o proprietário urbano, visto que a cooperação lhes permitia comprar a grosso aos produtores e consumir os objetos necessários à existência por um preço mais barato, minorados do lucro do intermediário - construir casas e habitá-las sem o encargo excessivo da renda - obter os capitais precisos para as necessidades quotidianas, sem os perigos da demasiada usura, etc. ${ }^{26}$. Na mesma linha, Sérvulo Correia afirma que «ao contrário da empresa capitalista, que tem como base um capital ou uma combinação de capitais que se trata de fazer reproduzir, procurando-Ihes um máximo de remuneração, a empresa cooperativa tem como estrutura um conjunto de homens que, necessitando dos respetivos serviços para fortificar a sua posição económica de compradores, trabalhadores, devedores, etc., se associaram para a fundar» ${ }^{27}$.

Tal como já foi destacado, na decorrência do escopo mutualístico da cooperativa, o cooperador assume a obrigação de participar na atividade da cooperativa.

Neste contexto, na cooperativa, os excedentes anuais resultantes das operações desta com os cooperadores não são verdadeiros lucros, mas significam um valor provisoriamente pago a mais pelos cooperadores à cooperativa ou pago a menos pela cooperativa aos cooperadores, como contrapartida da participação destes na atividade da cooperativa. O excedente resulta, assim, de operações da cooperativa com os seus cooperadores, sendo gerado à custa destes, constituindo o resultado de uma renúncia tácita dos cooperadores a vantagens cooperativas imediatas.

Esta definição torna evidente que o conceito de excedente cooperativo decorre da prossecução do escopo mutualístico pela cooperativa.

Este excedente poderá retornar aos cooperadores, tal como resulta do $\mathrm{n} .{ }^{\circ} 1$ do art. $100 .^{\circ}$ do CCoop, quando dispõe que "os excedentes anuais líquidos, com exceção dos provenientes de operações realizadas com terceiros, que restarem depois do eventual pagamento de juros pelos títulos de capital e das reversões para as diversas reservas, poderão retornar aos cooperadores».

26 Cunha Gonçalves, Comentário ao Código Comercial português, volume I (Lisboa: Empreza Editora J. B., 1914): 541.

27 Sérvulo Correia, "Elementos de um regime jurídico da cooperação», Estudos Sociais e Cooperativos, n. ${ }^{\circ} 17$ (Ano V, Março 1966): 162. 
Do preceito resulta de forma inequívoca que apenas os excedentes resultantes de operações da cooperativa com os cooperadores poderão retornar a estes. Já os benefícios provenientes de operações com terceiros não poderão ser repartidos pelos cooperadores, sendo obrigatoriamente afetados a reservas irrepartíveis (art. $99 .^{\circ}$ do CCoop). O fundamento deste regime legal está no facto de, nas cooperativas, os resultados das operações com terceiros serem juridicamente encarados como lucros e não como verdadeiros excedentes cooperativos, uma vez que não foram realizados no âmbito de uma atividade mutualista, sendo que a impossibilidade da sua repartição entre os cooperadores é uma das maiores evidências da natureza não lucrativa das cooperativas.

O retorno, entendido como o instrumento técnico de atribuição ao cooperador do excedente, surge, então, como uma distribuição diferida do mesmo, significando a devolução ou a restituição que se faz ao membro de uma dada cooperativa, ao fazer o balanço e a liquidação do exercício económico, daquilo que já é seu desde o início da atividade. O retorno de excedentes funcionará, deste modo, como uma correção a posteriori, através da qual se devolverá, a quem formou o excedente, a diferença entre o preço praticado e o custo, ou a diferença entre as receitas líquidas e os adiantamentos laborais pagos, diferença esta determinada com exatidão no final de cada exercício.

A distribuição do retorno entre os cooperadores será proporcional às operações feitas por cada um deles com a cooperativa, no referido exercício. Sendo os excedentes, resultantes de operações da cooperativa com os seus cooperadores, gerados à custa dos próprios membros da cooperativa, compreende-se, assim, que, quando ocorra o retorno, ele corresponda ao volume dessas operações e não ao número de títulos de capital que cada um detenha 28.

Neste contexto, as cooperativas deverão ser qualificadas como entidades do setor não lucrativo e, por conseguinte, deverão ficar sujeitas ao regime de normalização contabilística previsto para as Entidades do Setor Não Lucrativo.

${ }^{28} \mathrm{~V}$., sobre a distinção entre excedente e lucro na cooperativa, Isabel-Gemma Fajardo García, «Orientaciones y aplicaciones del principio de participación económica», CIRIEC-España, Revista Jurídica de Economía Social y Cooperativa, Monográfico, n. ${ }^{\circ} 27$ (2015), 215 e ss. 


\section{Evidência empírica: o caso das cooperativas da região demarcada do douro}

O estudo empírico versa sobre o cálculo do impacto da aplicação do § 10. ${ }^{\circ}$ da NCRF 27 no reconhecimento contabilístico das entradas para o capital social das Adegas Cooperativas da Região Demarcada do Douro (RDD).

A escolha da amostra recaiu sobre estas entidades por se tratar de um grupo homogéneo de cooperativas, que, para além das características inerentes à sua natureza jurídica enquanto cooperativas, detêm nos seus ativos elevados stocks, durante vários anos, originados pelo longo período de produção (envelhecimento) do Vinho do Porto. A manutenção desses stocks tem inevitavelmente reflexo no passivo, através de uma elevada alavancagem financeira, gerada pelas elevadas necessidades de financiamento externo, por terem de pagar aos cooperadores as uvas entregues, destinadas à produção de certos vinhos envelhecidos, muito antes da venda do produto acabado, como acontece com o Vinho do Porto.

Com base na informação recolhida, elaborou-se a Tabela 1, na qual se apresenta o ponto de situação, em termos de exercício de atividade, à data de 31 de dezembro de 2015 .

Tabela 1. Situação das adegas cooperativas da RDD, em 31-12-2015

\begin{tabular}{|c|c|c|c|c|c|}
\hline \multirow[b]{2}{*}{ N. ${ }^{\circ}$} & \multirow[b]{2}{*}{ Designação } & & \multicolumn{3}{|c|}{ Situação } \\
\hline & & & Ativa & \begin{tabular}{|c|} 
Dados \\
indisponíveis
\end{tabular} & $\begin{array}{l}\text { Inativa/ } \\
\text { extinta }\end{array}$ \\
\hline 1 & Adega Coop. Alijó, C.R.L. & & $\sqrt{ }$ & & \\
\hline 2 & Adega Coop. Armamar, C.R.L. & a) & & & $x$ \\
\hline 3 & Adega Coop. Favaios, C.R.L. & & $\sqrt{ }$ & & \\
\hline 4 & Adega Coop. Freixo de Espada-à-Cinta, C.R.L. & & $\sqrt{ }$ & & \\
\hline 5 & Adega Coop. Lamego, C.R.L. & b) & & & $x$ \\
\hline 6 & Adega Coop. Mêda, C.R.L. & d) & & $x$ & \\
\hline 7 & Adega Coop. Mesão Frio, C.R.L. & & $\sqrt{ }$ & & \\
\hline 8 & Adega Coop. Moncorvo, C.R.L. & & $\sqrt{ }$ & & \\
\hline 9 & Adega Coop. Murça, C.R.L. & & $\sqrt{ }$ & & \\
\hline 10 & Adega Coop. Penajoia, C.R.L. & d) & & $x$ & \\
\hline 11 & Adega Coop. Sabrosa, C.R.L. & & $\sqrt{ }$ & & \\
\hline 12 & Adega Coop. Sanfins do Douro, C.R.L. & b) & & & $x$ \\
\hline 13 & Coop. Agrícola de São João da Pesqueira, C.R.L. & d) & & $x$ & \\
\hline
\end{tabular}




\begin{tabular}{|c|c|c|c|c|c|}
\hline \multirow[b]{2}{*}{ N. ${ }^{\circ}$} & \multirow[b]{2}{*}{ Designação } & & \multicolumn{3}{|c|}{ Situação } \\
\hline & & & Ativa & \begin{tabular}{|c|} 
Dados \\
indisponíveis
\end{tabular} & $\begin{array}{l}\text { Inativa/ } \\
\text { extinta }\end{array}$ \\
\hline 14 & Adega Coop. Trevões, C.R.L. & & $\sqrt{ }$ & & \\
\hline 15 & Adega Coop. Vale da Teja, C.R.L. & & $\sqrt{ }$ & & \\
\hline 16 & Adega Coop. Vale do Douro de Tabuaço, C.R.L. & a) & & & $x$ \\
\hline 17 & Adega Coop. Vila Flor, C.R.L. & c) & & & $x$ \\
\hline 18 & Adega Coop. Vila Nova de Foz Côa, C.R.L. & c) & & & $x$ \\
\hline 19 & Adega Coop. Vila Real, C.R.L. & & $\sqrt{ }$ & & \\
\hline 20 & Adega Coop. Regional de Pegarinhos, C.R.L. & d) & & $x$ & \\
\hline 21 & Caves Santa Marta - Vinhos e Derivados, C.R.L. & & $\sqrt{ }$ & & \\
\hline 22 & Coop. Viticultores e Olivicultores de Freixo Numão, C.R.L. & & $\sqrt{ }$ & & \\
\hline 23 & Caves Vale do Rodo, C.R.L. & & $\sqrt{ }$ & & \\
\hline 22 & Coop. Viticultores e Olivicultores de Freixo Numão, C.R.L. & & $\sqrt{ }$ & & \\
\hline 23 & Caves Vale do Rodo, C.R.L. & & $\sqrt{ }$ & & \\
\hline
\end{tabular}

Fonte: Elaboração dos autores.

Legenda

a) Extinta após fusão, em 2004, com a cooperativa Caves Vale do Rodo, C.R.L.;

b) Não presta contas há mais de 7 anos;

c) Encerrada;

d) Não foi possivel obter informação contabilística/atividade.

Dos vários contactos efetuados, no âmbito do processo de recolha de informação, designadamente com a CASES, concluiu-se que, no final de 2015 apenas 13 cooperativas vitivinícolas da RDD se encontravam ativas, tal como resulta da Tabela 1. Admite-se, no entanto, que o estado de inatividade de algumas delas possa ser temporário, não se podendo concluir pela sua extinção, por falta de informação. Assim, em termos estatísticos, a amostra do presente estudo contempla as 13 cooperativas consideradas ativas pela CASES, naquela data, o que corresponde também à população das cooperativas vitivinícolas da RDD.

\section{Método: aplicação de rácios}

Tendo em conta o principal objetivo deste estudo, traduzido na avaliação do impacto da aplicação do § $10{ }^{\circ}$ da NCRF 27 na capacidade de financiamento das cooperativas da RDD, procedeu-se ao cálculo dos rácios de endividamento e liquidez, antes e após a aplicação daquela norma aos balanços daquelas cooperativas, para os exercícios de 2011 a 2015, ou seja após entrada em vigor do SNC. 
Os rácios proporcionam informação complementar à do balanço sobre o equilíbrio financeiro de uma entidade, permitindo avaliar a capacidade desta para fazer face aos compromissos de forma adequada e atempada.

\section{Debt to equity ratio}

Este rácio visa demonstrar a proporção entre os capitais alheios e os capitais próprios no financiamento de uma entidade. Os resultados obtidos indicam que este rácio se degradou após a aplicação do $\S 10^{\circ}$ da NCRF 27, isto é, passou a ser superior a 1 para a generalidade das cooperativas e em todos os períodos analisados, traduzindo um maior nível de endividamento e, consequentemente, menor solidez financeira.

\section{Rácio de solvabilidade}

Este rácio permite determinar a proporção relativa dos ativos da entidade que são financiados por capitais próprios versus por capitais alheios. Após a aplicação do $\S 10^{\circ}$ da NCRF 27, o rácio degradou-se, isto é, a estrutura de financiamento dos ativos da generalidade das cooperativas foi alterada, refletindo o aumento do financiamento através de capitais alheios, em detrimento do financiamento através de capitais próprios.

\section{Rácio de autonomia financeira}

Este rácio permite avaliar qual a percentagem do ativo da entidade que está a ser financiada através de capitais próprios. Constitui um indicador de solidez financeira, pelo que quanto menor for este rácio maior o risco de insolvência da entidade. Após a aplicação do $\S 10{ }^{\circ}$ da NCRF 27, à semelhança do que havia sucedido com o rácio de solvabilidade, este indicador degradou-se, isto é, a estrutura de financiamento dos ativos alterou-se para a generalidade das cooperativas, evidenciando o aumento do financiamento através de capitais alheios.

\section{Rácio de dependência financeira}

Este rácio exprime a participação dos capitais alheios no financiamento do ativo da empresa. Após a aplicação do $\S 10 .^{\circ}$ da NCRF 27, 
verifica-se que este rácio aumentou na mesma proporção em que o indicador de autonomia financeira havia diminuído, uma vez que corresponde ao seu complementar, isto é, verificou-se o aumento do endividamento na mesma proporção em que o capital próprio diminuiu.

Rácio de cobertura dos ativos não correntes

Este rácio permite aferir a participação dos capitais permanentes no financiamento dos ativos com caráter permanente. Se este indicador for inferior a $100 \%$ tal significa que o financiamento dos ativos não correntes e dos inventários (que no caso particular das cooperativas da RDD têm caráter de permanência) não está a ser totalmente assegurado através de capitais com caráter permanente. Após a aplicação do $\S 10 .^{\circ}$ da NCRF 27, verifica-se que este rácio aumentou, em virtude da diminuição do montante dos capitais com caráter permanente na estrutura de financiamento das entidades.

Rácio de liquidez reduzida

Este rácio evidencia a capacidade das entidades solverem os seus compromissos de curto prazo, com recurso aos seus ativos circulantes, excluindo os inventários. Da interpretação dos resultados verificou-se que, antes da aplicação da norma, em média as entidades analisadas evidenciavam que esses recursos correspondiam a mais de $50 \%$ dos compromissos assumidos. Após a aplicação do $\S 10{ }^{\circ}$ da NCRF 27, verificou-se que este rácio diminuiu, em virtude da diminuição do montante dos capitais com caráter permanente, em detrimento do passivo exigível a curto prazo, que aumentou, pois passou a incluir o capital social.

Impacto da variação sofrida pelos rácios

Calculados os rácios, importa avaliar se a variação sofrida é ou não relevante do ponto de vista estatístico, isto é, se a degradação daqueles indicadores é significativa a ponto de afetar a opinião dos utilizadores da informação financeira, designadamente a banca, agravando as dificuldades de obtenção de crédito por parte destas cooperativas.

Dado que as amostras não são independentes, uma vez que as duas são formadas por pares de observações efetuadas sobre as mes- 
mas entidades, pertencentes à mesma população, embora em dois cenários diferentes, isto é, "antes e depois ${ }^{29}$ » da aplicação da NCRF 27, a literatura apelida-as de amostras emparelhadas ou amostras correlacionadas.

Assim, a metodologia utilizada para verificar se a variação sofrida pelos rácios de endividamento e liquidez é estatisticamente significativa consistirá no cálculo da diferença entre as médias dos rácios das cooperativas da RDD, relativos aos anos 2011 a 2015. Tal permitirá concluir se de facto a aplicação do $\S 10 .^{\circ}$ da NCRF 27 deteriorou os rácios de forma significativa.

O estudo em apreço configura um cenário de teste de hipóteses, com base na diferença entre médias de amostras emparelhadas, de pequena dimensão ( $n 1, n 2 \leq 30)$, com distribuição normal, pelo que irá recorrer-se ao uso do teste $t$-Student.

\section{i. DEFINIÇÃO DAS HIPÓTESES}

Como referido anteriormente, pretende-se verificar se a média dos rácios daquelas entidades, após a aplicação do $\S 10^{\circ}$ da NCRF 27, é significativamente menor que a média antes da sua aplicação. Tal constitui o nosso ponto de partida e servirá para verificar se aquela norma teve ou não impacto significativo naqueles indicadores, isto é, se as médias antes e após a aplicação da norma são estatisticamente diferentes. Neste sentido, de acordo com Coelho et al ${ }^{30}$, enunciam-se as seguintes hipóteses de teste:

$H_{0}$ - A variação sofrida pelo rácio não é significativa: $\mu \mathrm{d}=0$

$H_{1}-A$ variação sofrida pelo rácio é significativa: $\mu \mathrm{d} \neq 0$ (num teste bilateral)

Em que: $\mu \mathrm{d}=\mu_{\text {depois }}-\mu_{\text {antes }}$

ii. DeFINIÇÃO dOS NÍVEIS DE SIGNIFICÂNCIA OU NÍVEIS DE CONFIANÇA

Pretende-se determinar o impacto, para cada um dos anos (2011 a 2015), ao nível de significância de 1\%. Contudo, se o impacto da

29 J. E. Freund e G. A. Simon, Estatística Aplicada - Economia Administração e Contabilidade, 9. ${ }^{a}$ Edição (Porto Alegre: Bookman, 2000): 229.

30 J. P. Coelho et al., Inferência Estatística - Com utilização do SPSS e G*power, 1. ${ }^{\text {a }}$ Edição (Lisboa: Edições Silabo, 2008). 
norma não for significativo ao nível de significância mais exigente, testar-se-á a hipótese aos níveis de 5\%, 10\% e 20\%:

$$
\begin{array}{ll}
\alpha=0,01 & 1-\alpha=0,99 \\
\alpha=0,05 & 1-\alpha=0,95 \\
\alpha=0,10 & 1-\alpha=0,90 \\
\alpha=0,20 & 1-\alpha=0,80
\end{array}
$$

iii. IDENTIFICAÇÃO dA VARIÁVEL DE TESTE

No presente estudo a amostra é composta pelas 13 cooperativas ativas da RDD, a qual corresponde ao universo da população. Dado que se trata de uma amostra de pequena dimensão ( $n<30$ elementos), a variável de teste a utilizar, para cada um dos anos, será a variável $t_{n-1}$, com $n$ - 1 graus de liberdade, a seguir explicitada:

$$
\boldsymbol{t}_{(\mathrm{n}-1)}=\frac{\mathrm{E}(\mathrm{X})-\mu_{\mathrm{c}}}{s / \sqrt{n}}
$$

Em que: $\mu 0=0$

Equação 1: Cálculo da variável de teste

iv. Definição do InterValo de ACEITAÇÃo das hipóteSES

Tal como anteriormente referido, trata-se de um teste bilateral (à esquerda e à direita), cujo valor crítico $\left(t_{\text {critico }}\right)$ obtido da tabela de distribuição t-Student será:

Se $t_{\text {amostral }}<t_{\text {critico }} \leftarrow$ Aceitar $H_{0}$

Se $t_{\text {amostral }}>t_{\text {critico }} \rightarrow$ Rejeitar $H_{0}$

Assim, sempre que o valor absoluto da variável de teste ( $\left.t_{\text {amostra }}\right)$ for superior ao valor crítico $\left(t_{\text {crítico }}\right)$, rejeita-se a $H_{0}$, o que significa que a variação sofrida pelos rácios deve ser considerada estatisticamente significativa. 
Variação verificada no Debt to equity ratio

Tabela 2. Variação do Debt to equity ratio, pela aplicação da NCRF 27

\begin{tabular}{|c|c|c|c|c|c|}
\hline \multirow{2}{*}{ Cooperativas } & \multicolumn{5}{|c|}{ Variação do rácio (p.p.) } \\
\hline & 2011 & 2012 & 2013 & 2014 & 2015 \\
\hline A. Coop. Alijó & $\mathrm{n} / \mathrm{a}$ & $\mathrm{n} / \mathrm{a}$ & $\mathrm{n} / \mathrm{a}$ & $\mathrm{n} / \mathrm{a}$ & $\mathrm{n} / \mathrm{a}$ \\
\hline A. Coop. Favaios & 0,69 & 0,69 & 0,68 & 0,65 & 0,68 \\
\hline A. Coop. F. Espada Cinta & 1,71 & 1,31 & 1,33 & 1,11 & 1,20 \\
\hline A. Coop. Mesão Frio & 1,14 & 1,12 & 1,16 & 1,29 & 1,33 \\
\hline A. Coop. Moncorvo & 0,98 & 1,10 & 5,49 & 4,23 & 3,49 \\
\hline A. Coop. Murça & 16,21 & 18,13 & 12,92 & 17,31 & 21,17 \\
\hline A. Coop. Sabrosa & 0,26 & 0,30 & 0,30 & 0,29 & 0,37 \\
\hline A. Coop. Trevões & 3,14 & 3,40 & 3,62 & 0,76 & 0,69 \\
\hline A. Coop. Vale da Teja & 1,84 & 0,58 & 0,50 & 0,51 & 0,48 \\
\hline A. Coop. Vila Real & 1,02 & 0,86 & 0,81 & 0,67 & 0,54 \\
\hline Caves Santa Marta & 1,34 & $\mathrm{n} / \mathrm{a}$ & $12.660,54$ & $\mathrm{n} / \mathrm{a}$ & 13,31 \\
\hline Coop. Vitic. OI. F. Numão & 0,35 & 0,49 & 0,60 & 0,72 & 27,39 \\
\hline Caves Vale do Rodo & $\mathrm{n} / \mathrm{a}$ & $\mathrm{n} / \mathrm{a}$ & $\mathrm{n} / \mathrm{a}$ & $\mathrm{n} / \mathrm{a}$ & $\mathrm{n} / \mathrm{a}$ \\
\hline Média das diferenças $(\mu d)$ & 2,61 & 2,80 & $2,74^{(1)}$ & 2,75 & 6,42 \\
\hline Variável de teste $\left(t_{n-1}\right)$ & 1,89 & 1,62 & 2,20 & 1,66 & 2,20 \\
\hline t-Student (Valor critico) & $1,81 * *$ & $1,38^{*}$ & $1,83 * *$ & $1,38^{*}$ & 1,81 ** \\
\hline
\end{tabular}

Fonte: Elaboração dos autores

Legenda:

(1) Neste cálculo não foi considerada a variação sofrida pela cooperativa Caves Santa Marta

$(12.660,54)$, devido a essa variação ser superior a 3 vezes o desvio padrão amostral, pelo que é estatisticamente negligenciável.

**** - Variação significativa a $1 \%$ de significância;

*** - Variação significativa a $5 \%$ de significância;

** - Variação significativa a 10\% de significância;

* - Variação significativa a $20 \%$ de significância;

Como definido anteriormente, se o valor da variável de teste fosse maior do que o valor crítico rejeitar-se-ia a HO. Pode assim concluir-se, com $80 \%$ de confiança (ou margem de erro de $20 \%$ ) para os períodos 2012 e 2014 e com 90\% de confiança (ou margem de erro de 10\%) para os períodos de 2011, 2013 e 2015, que a variação sofrida pelo Debt to equity ratio, após a aplicação da NCRF 27, é estatisticamente significativa. 
Variação verificada no rácio Solvabilidade

Tabela 3. Variação do rácio Solvabilidade, pela aplicação da NCRF 27

\begin{tabular}{|c|c|c|c|c|c|}
\hline \multirow{2}{*}{ Cooperativas } & \multicolumn{5}{|c|}{ Variação do rácio (p.p.) } \\
\hline & 2011 & 2012 & 2013 & 2014 & 2015 \\
\hline A. Coop. Alijó & $-7,84$ & $-6,88$ & $-5,72$ & $-5,86$ & $-5,50$ \\
\hline A. Coop. Favaios & $-20,69$ & $-21,41$ & $-21,12$ & $-23,24$ & $-21,91$ \\
\hline A. Coop. F. Espada Cinta & $-37,68$ & $-40,87$ & $-35,57$ & $-48,64$ & $-35,52$ \\
\hline A. Coop. Mesão Frio & $-22,25$ & $-24,95$ & $-24,54$ & $-22,47$ & $-21,68$ \\
\hline A. Coop. Moncorvo & $-57,22$ & $-44,74$ & $-78,38$ & $-63,97$ & $-84,01$ \\
\hline A. Coop. Murça & $-63,47$ & $-68,60$ & $-68,30$ & $-63,54$ & $-66,34$ \\
\hline A. Coop. Sabrosa & $-27,85$ & $-25,00$ & $-22,40$ & $-28,13$ & $-23,90$ \\
\hline A. Coop. Trevões & $-28,10$ & $-24,39$ & $-22,03$ & $-30,09$ & $-37,66$ \\
\hline A. Coop. Vale da Teja & $-19,73$ & $-38,71$ & $-41,82$ & $-40,52$ & $-41,40$ \\
\hline A. Coop. Vila Real & $-98,19$ & $-109,38$ & $-108,08$ & $-147,57$ & $-157,96$ \\
\hline Caves Santa Marta & $-13,91$ & $-9,88$ & $-11,83$ & $-12,14$ & $-15,03$ \\
\hline Coop. Vitic. OI. F. Numão & $-15,81$ & $-11,40$ & $-10,09$ & $-43,05$ & $-17,26$ \\
\hline Caves Vale do Rodo & $-10,43$ & $-11,14$ & $-11,18$ & $-11,45$ & $-11,67$ \\
\hline Média das diferenças $(\mu d)$ & $-32,55$ & $-33,64$ & $-35,47$ & $-41,59$ & $-41,53$ \\
\hline Variável de teste $\left(t_{n-1}\right)$ & 4,52 & 4,24 & 4,12 & 4,06 & 3,61 \\
\hline t-Student (Valor critico) & $3.05 * * * *$ & $3.05 * * * *$ & $3.05 * * * *$ & $3.05 * * * *$ & $3.05 * * * *$ \\
\hline
\end{tabular}

Fonte: Elaboração dos autores

Legenda:

**** - Variação significativa a $1 \%$ de significância;

*** - Variação significativa a $5 \%$ de significância;

** - Variação significativa a 10\% de significância;

* - Variação significativa a $20 \%$ de significância;

Como definido anteriormente, como o valor da variável de teste é maior do que o valor crítico, rejeita-se a Ho. Pode assim concluir-se, com 99\% de confiança (ou margem de erro de 1\%), que a variação sofrida pelo rácio de solvabilidade, após a aplicação da NCRF 27, é estatisticamente significativa para todos os períodos analisados. Neste contexto, dispensou-se a análise para os restantes níveis de significância. 
Variação verificada no rácio Autonomia financeira

\section{Tabela 4. Variação do rácio Autonomia financeira, pela aplicação da NCRF 27}

\begin{tabular}{|c|c|c|c|c|c|}
\hline \multirow{2}{*}{ Cooperativas } & \multicolumn{5}{|c|}{ Variação do rácio (p.p.) } \\
\hline & 2011 & 2012 & 2013 & 2014 & 2015 \\
\hline A. Coop. Alijó & $-21,48$ & $-24,33$ & $-29,57$ & $-33,57$ & $-34,96$ \\
\hline A. Coop. Favaios & $-8,58$ & $-8,76$ & $-8,64$ & $-9,02$ & $-8,83$ \\
\hline A. Coop. F. Espada Cinta & $-16,88$ & $-16,34$ & $-15,05$ & $-17,06$ & $-14,55$ \\
\hline A. Coop. Mesão Frio & $-10,56$ & $-11,35$ & $-11,34$ & $-11,03$ & $-10,85$ \\
\hline A. Coop. Moncorvo & $-17,76$ & $-16,19$ & $-35,12$ & $-29,64$ & $-33,18$ \\
\hline A. Coop. Murça & $-35,52$ & $-37,56$ & $-36,40$ & $-35,72$ & $-37,20$ \\
\hline A. Coop. Sabrosa & $-6,74$ & $-6,79$ & $-6,38$ & $-7,07$ & $-7,29$ \\
\hline A. Coop. Trevões & $-16,05$ & $-14,69$ & $-13,76$ & $-11,20$ & $-12,28$ \\
\hline A. Coop. Vale da Teja & $-11,02$ & $-11,57$ & $-11,30$ & $-11,15$ & $-10,98$ \\
\hline A. Coop. Vila Real & $-23,61$ & $-22,85$ & $-22,14$ & $-22,60$ & $-20,49$ \\
\hline Caves Santa Marta & $-7,89$ & $-10,34$ & $-10,58$ & $-11,68$ & $-11,82$ \\
\hline Coop. Vitic. OI. F. Numão & $-5,61$ & $-5,18$ & $-5,06$ & $-13,47$ & $-13,91$ \\
\hline Caves Vale do Rodo & $-11,13$ & $-11,65$ & $-11,72$ & $-12,33$ & $-12,54$ \\
\hline Média das diferenças $(\mu d)$ & $-14,83$ & $-15,20$ & $-16,70$ & $-17,35$ & $-17,61$ \\
\hline Variável de teste $\left(t_{n-1}\right)$ & 6,36 & 6,25 & 5,65 & 6,41 & 6,05 \\
\hline t-Student (Valor critico) & $3,05 * * * *$ & $3,05^{* * * *}$ & $3,05^{* * * *}$ & $3,05^{\star * * *}$ & $3,05^{* * * *}$ \\
\hline
\end{tabular}

Fonte: Elaboração dos autores

Legenda:

$* * * *$ - Variação significativa a $1 \%$ de significância;

*** - Variação significativa a $5 \%$ de significância;

** - Variação significativa a 10\% de significância;

* - Variação significativa a 20\% de significância.

Como definido anteriormente, como o valor da variável de teste é maior do que o valor crítico, rejeita-se a HO. Pode assim concluir-se, com 99\% de confiança (ou margem de erro de 1\%), que a variação sofrida pelo rácio de autonomia financeira após a aplicação da NCRF 27 é estatisticamente significativa em todos os períodos analisados. Deste modo, dispensou-se a análise para os restantes níveis de significância. 
Variação verificada no rácio Dependência financeira

Tabela 5. Variação do rácio Dependência financeira, pela aplicação da NCRF 27

\begin{tabular}{|c|c|c|c|c|c|}
\hline \multirow{2}{*}{ Cooperativas } & \multicolumn{5}{|c|}{ Variação do rácio (p.p.) } \\
\hline & 2011 & 2012 & 2013 & 2014 & 2015 \\
\hline A. Coop. Alijó & 21,48 & 24,33 & 29,57 & 33,57 & 34,96 \\
\hline A. Coop. Favaios & 8,58 & 8,76 & 8,64 & 9,02 & 8,83 \\
\hline A. Coop. F. Espada Cinta & 16,88 & 16,34 & 15,05 & 17,06 & 14,55 \\
\hline A. Coop. Mesão Frio & 10,56 & 11,35 & 11,34 & 11,03 & 10,85 \\
\hline A. Coop. Moncorvo & 17,76 & 16,19 & 35,12 & 29,64 & 33,18 \\
\hline A. Coop. Murça & 35,52 & 37,56 & 36,40 & 35,72 & 37,20 \\
\hline A. Coop. Sabrosa & 6,74 & 6,79 & 6,38 & 7,07 & 7,29 \\
\hline A. Coop. Trevões & 16,05 & 14,69 & 13,76 & 11,20 & 12,28 \\
\hline A. Coop. Vale da Teja & 11,02 & 11,57 & 11,30 & 11,15 & 10,98 \\
\hline A. Coop. Vila Real & 23,61 & 22,85 & 22,14 & 22,60 & 20,49 \\
\hline Caves Santa Marta & 7,89 & 10,34 & 10,58 & 11,68 & 11,82 \\
\hline Coop. Vitic. OI. F. Numão & 5,61 & 5,18 & 5,06 & 13,47 & 13,91 \\
\hline Caves Vale do Rodo & 11,13 & 11,65 & 11,72 & 12,33 & 12,54 \\
\hline Média das diferenças $(\mu d)$ & 14,83 & 15,20 & 16,70 & 17,35 & 17,61 \\
\hline Variável de teste $\left(t_{n-1}\right)$ & 6,36 & 6,25 & 5,65 & 6,41 & 6,05 \\
\hline t-Student (Valor critico) & $3,05 * * * *$ & $3,05 * * * *$ & $3,05 * * * *$ & $3,05 * * * *$ & $3,05 * * * *$ \\
\hline
\end{tabular}

Fonte: Elaboração dos autores

Legenda:

$* * * *$ - Variação significativa a $1 \%$ de significância;

*** - Variação significativa a $5 \%$ de significância;

** - Variação significativa a 10\% de significância;

* - Variação significativa a 20\% de significância;

Como definido anteriormente, como o valor da variável de teste é maior do que o valor crítico, rejeita-se a HO. Pode assim concluir-se, com 99\% de confiança (ou margem de erro de 1\%), que a variação sofrida pelo rácio dependência financeira, após a aplicação da NCRF 27, é estatisticamente significativa, para todos os períodos analisados. Assim, dispensou-se a análise para os restantes níveis de significância. 
Variação verificada no rácio Cobertura dos ativos não correntes

\section{Tabela 6. Variação do rácio Cobertura dos ativos não correntes, pela aplicação da NCRF 27}

\begin{tabular}{|c|c|c|c|c|c|}
\hline \multirow{2}{*}{ Cooperativas } & \multicolumn{5}{|c|}{ Variação do rácio (p.p.) } \\
\hline & 2011 & 2012 & 2013 & 2014 & 2015 \\
\hline A. Coop. Alijó & $-26,37$ & $-31,71$ & $-36,99$ & $-42,44$ & $-40,74$ \\
\hline A. Coop. Favaios & $-9,57$ & $-9,72$ & $-9,64$ & $-10,14$ & $-10,30$ \\
\hline A. Coop. F. Espada Cinta & $-19,35$ & $-25,81$ & $-18,75$ & $-20,53$ & $-19,45$ \\
\hline A. Coop. Mesão Frio & $-15,99$ & $-15,20$ & $-13,27$ & $-14,38$ & $-13,68$ \\
\hline A. Coop. Moncorvo & $-32,39$ & $-32,44$ & $-60,01$ & $-57,88$ & $-52,43$ \\
\hline A. Coop. Murça & $-37,44$ & $-41,40$ & $-38,70$ & $-41,55$ & $-43,08$ \\
\hline A. Coop. Sabrosa & $-10,34$ & $-10,33$ & $-9,06$ & $-9,68$ & $-10,00$ \\
\hline A. Coop. Trevões & $-19,78$ & $-20,55$ & $-20,97$ & $-15,52$ & $-16,24$ \\
\hline A. Coop. Vale da Teja & $-12,10$ & $-16,37$ & $-15,00$ & $-12,39$ & $-12,67$ \\
\hline A. Coop. Vila Real & $-41,93$ & $-41,96$ & $-42,73$ & $-40,44$ & $-33,51$ \\
\hline Caves Santa Marta & $-8,64$ & $-10,69$ & $-11,18$ & $-12,25$ & $-12,41$ \\
\hline Coop. Vitic. OI. F. Numão & $-13,06$ & $-5,70$ & $-7,09$ & $-15,37$ & $-17,67$ \\
\hline Caves Vale do Rodo & $-11,87$ & $-12,88$ & $-12,51$ & $-13,11$ & $-13,65$ \\
\hline Média das diferenças $(\mu d)$ & $-19,91$ & $-21,14$ & $-22,76$ & $-23,51$ & $-22,75$ \\
\hline Variável de teste $\left(t_{n-1}\right)$ & 6,41 & 6,18 & 4,98 & 5,27 & 5,68 \\
\hline t-Student (Valor critico) & $3,05 * * * *$ & $3,05 * * * *$ & $3,05 * * * *$ & $3,05 * * * *$ & $3,05 * * * *$ \\
\hline
\end{tabular}

Fonte: Elaboração dos autores

Legenda:

**** - Variação significativa a $1 \%$ de significância;

*** - Variação significativa a 5\% de significância;

** - Variação significativa a 10\% de significância;

* - Variação significativa a 20\% de significância;

Como definido anteriormente, como o valor da variável de teste é maior do que o valor crítico, rejeita-se a HO. Pode assim concluir-se, com $99 \%$ de confiança (ou margem de erro de 1\%), que a variação sofrida pelo rácio cobertura dos ativos não correntes, após a aplicação da NCRF 27, é estatisticamente significativa, em todos os períodos analisados. Assim, dispensou-se a análise para os restantes níveis de significância. 
Variação verificada no rácio Liquidez reduzida

Tabela 7. Variação do rácio Liquidez reduzida, pela aplicação da NCRF 27

\begin{tabular}{|c|c|c|c|c|c|}
\hline \multirow{2}{*}{ Cooperativas } & \multicolumn{5}{|c|}{ Variação do rácio (p.p.) } \\
\hline & 2011 & 2012 & 2013 & 2014 & 2015 \\
\hline A. Coop. Alijó & $-2,27$ & $-2,16$ & $-54,96$ & $-39,53$ & $-17,54$ \\
\hline A. Coop. Favaios & $-4,08$ & $-3,89$ & $-4,48$ & $-4,48$ & $-4,88$ \\
\hline A. Coop. F. Espada Cinta & $-8,76$ & $-28,04$ & $-16,43$ & $-23,08$ & $-18,27$ \\
\hline A. Coop. Mesão Frio & $-7,55$ & $-6,33$ & $-3,58$ & $-5,24$ & $-4,48$ \\
\hline A. Coop. Moncorvo & $-25,85$ & $-22,41$ & $-32,51$ & $-31,21$ & $-30,85$ \\
\hline A. Coop. Murça & $-19,60$ & $-17,10$ & $-9,26$ & $-16,66$ & $-15,65$ \\
\hline A. Coop. Sabrosa & $-9,70$ & $-8,56$ & $-6,62$ & $-7,58$ & $-6,47$ \\
\hline A. Coop. Trevões & $-5,30$ & $-6,95$ & $-12,81$ & $-13,61$ & $-17,33$ \\
\hline A. Coop. Vale da Teja & $-1,76$ & $-16,33$ & $-12,54$ & $-4,55$ & $-5,51$ \\
\hline A. Coop. Vila Real & $-42,89$ & $-49,80$ & $-52,09$ & $-65,11$ & $-61,37$ \\
\hline Caves Santa Marta & $-3,59$ & $-29,25$ & $-0,79$ & $-62,94$ & $-50,45$ \\
\hline Coop. Vitic. OI. F. Numão & $-21,79$ & $-2,91$ & $-6,51$ & $-14,03$ & $-6,06$ \\
\hline Caves Vale do Rodo & $-2,94$ & $-4,04$ & $-2,03$ & $-1,89$ & $-3,09$ \\
\hline Média das diferenças $(\mu d)$ & $-12,01$ & $-15,21$ & $-16,51$ & $-22,30$ & $-18,61$ \\
\hline Variável de teste $\left(t_{n-1}\right)$ & 3,54 & 3,89 & 3,24 & 3,72 & 3,63 \\
\hline t-Student (Valor critico) & $3,05 * * * *$ & $3,05 * * * *$ & $3,05 * * * *$ & $3,05 * * * *$ & $3,05 * * * *$ \\
\hline
\end{tabular}

Fonte: Elaboração dos autores

Legenda:

**** - Variação significativa a $1 \%$ de significância;

*** - Variação significativa a $5 \%$ de significância;

** - Variação significativa a 10\% de significância;

* - Variação significativa a 20\% de significância;

Interpretação dos resultados

Os resultados desta análise confirmam o impacto negativo que a aplicação do $\S 10 .^{\circ}$ da NCRF 27 provoca em todos os rácios de endividamento e liquidez analisados, em virtude da classificação do capital social cooperativo como passivo financeiro. Daqui resulta que a aplicação desta norma contabilística afeta significativamente a estabilidade financeira de todas as cooperativas analisadas. Por esse motivo, as cooperativas que integram a amostra preparam as suas demonstrações 
financeiras segundo o SNC, mas não aplicam a disposição prevista no $\S 10 .^{\circ}$ da NCRF 27, seguindo o Parecer da Comissão de Normalização Contabilística acima referido, classificando, por isso, o capital social como recurso próprio.

Para além da referida degradação significativa de todos os rácios de endividamento e liquidez analisados, validada através de método estatístico, a aplicação da NCRF 27 provocou, igualmente, uma clara alteração da estrutura do balanço daquelas entidades, designadamente, a diminuição do financiamento dos ativos através de capitais permanentes, em detrimento do aumento do financiamento através de capitais alheios. Verificou-se, também, que, em 2015, caso se aplicasse a referida norma contabilística, cerca de um terço das cooperativas analisadas ficaria em situação de falência técnica, situação que, inequivocamente, dificultaria o acesso ao crédito junto da banca - recurso essencial ao normal desenvolvimento da sua atividade, por força de o seu ciclo de exploração ser bastante desfasado, o que gera necessidades de financiamento permanentes.

\section{Conclusões}

No ordenamento português não existe um tratamento contabilístico específico e diferenciado para as cooperativas face às sociedades comerciais, pelo que estas estão sujeitas às normas internacionais de contabilidade, designadamente à IAS 32, com o risco de o capital social ser qualificado, contabilisticamente, como um recurso alheio e não como um recurso próprio, porque reembolsável em caso de demissão do cooperador.

Este direito de demissão e consequente direito ao reembolso decorrem do princípio cooperativo da adesão voluntária e livre.

Tendo em conta as exigências constantes da «IFRIC 2», as alterações introduzidas, aquando da reforma do Código Cooperativo em 2015, não são suficientes para impedirem a qualificação contabilística do capital social cooperativo como um passivo financeiro.

Mantém-se a proibição da supressão do direito de demissão, permitindo-se apenas que os estatutos limitem tal direito "estabelecendo regras e condições para o seu exercício», pelo que o reembolso não pode ser recusado incondicionalmente pelo órgão de administração da cooperativa em caso de demissão do cooperador, rejeitando-se a proibição incondicional absoluta de que fala a «IFRIC 2 ».

Também a proibição incondicional parcial é afastada, pois, não obstante o legislador admitir a possibilidade de estatutariamente se prever 
que o órgão de administração suspenda o reembolso quando num exercício económico o montante dos títulos de capital a reembolsar supere uma determinada percentagem do capital social que neles se estabeleça, tal previsão não é suficiente para impedir a qualificação contabilística do capital social cooperativo como um passivo financeiro, pois sujeita-se esta decisão de suspensão do reembolso a condicionalismos, traduzidos na obrigação de fundamentação por parte do órgão de administração e na sujeição a ratificação da assembleia geral. Estes condicionalismos têm como consequência que a proibição parcial deixe de ser incondicional, não respeitando, deste modo, as exigências constantes da «IFRIC 2».

$\mathrm{Na}$ base desta opção legislativa, que é inquestionavelmente a que melhor preserva a identidade cooperativa, respeitando o princípio cooperativo da adesão voluntária e livre, estará, desde logo, a circunstância de, em Portugal, a Comissão de Normalização Contabilística ter proferido um parecer, em 15 de março de 2012, nos termos do qual o capital social cooperativo deverá ser classificado contabilisticamente como um recurso próprio.

Este parecer tem, no entanto, um carácter meramente informativo, não sendo suficiente para a resolução do problema da qualificação contabilística do capital social cooperativo.

Em Portugal, o risco de o capital social cooperativo ser classificado contabilisticamente como passivo persiste, com as graves implicações económico-financeiras daí resultantes, e que foram evidenciadas pelo estudo empírico, cujos resultados confirmaram que a aplicação do § $10{ }^{\circ}$ da NCRF 27 teria consequências graves ao nível dos rácios de endividamento e liquidez das cooperativas, o que afetaria significativamente a sua capacidade de obtenção de financiamento externo.

Neste contexto, defendemos uma intervenção legislativa que permita a sujeição das cooperativas a um tratamento contabilístico específico e diferenciado que respeite a caraterística da variabilidade do capital social, decorrente do direito ao reembolso das entradas em caso de demissão do cooperador, ao abrigo do princípio cooperativo da adesão voluntária e livre.

\section{Bibliografia}

ANDICOECHEA, Lorea e Miguel A. ZUBIAURRE. 2012. «Equity-Liability Accounting Debate in Worker Cooperative Entities Members' Shares», Journal of Co-Operative Accounting and Reporting, n. ${ }^{\circ} \mathrm{V} 1: 28-46$

CORREIA, Sérvulo. 1966. "Elementos de um regime jurídico da cooperação», Estudos Sociais e Cooperativos, n. ${ }^{\circ} 17:$ 110-174. 
COELHO, J.P. et al. 2008. Inferência Estatística - Com utilização do SPSS e G* power, 1. ${ }^{a}$ Edição. Lisboa: Edições Silabo..

DETILLEUX, Jean-Claude e Caroline NAETT. 2005. "Les Cooperatives face aux Normes Comptables Internationales: Le cas de I' IAS 32», RECMA - Revue Internationale de L'Économie Sociale, n. ${ }^{\circ}$ 295: 7-19.

FAJARDO GARCÍA, Isabel-Gemma. 2005. "La masa activa y pasiva en el concurso de Cooperativas», in: Estudios sobre la Ley Concursal. Libro Homenaje a Manuel Olivencia. Tomo V. Madrid-Barcelona

FAJARDO GARCÍA, Isabel-Gemma. 2016. "La reforma del Código Cooperativo Portugués desde una perspectiva de Derecho Comparado», Revista de Ciências Empresariais e Jurídicas, n. ${ }^{\circ} 27:$ 50-66.

FAJARDO GARCÍA, Isabel-Gemma. 2015. "Orientaciones y aplicaciones del principio de participación económica». CIRIEC-España, Revista Jurídica de Economía Social y Cooperativa, Monográfico, n. ${ }^{\circ}$ 27: 205-241.

FERNÁNDEZ FEIJOO SOUTO, Belén e María José CABALEIRO CASAL. 2007. «Clasificación del capital social de la cooperativa: una visión crítica», CIRIEC-España, Revista de Economía Pública Social y Cooperativa, n. ${ }^{\circ}$ 58: 7-29.

FREUND, J. E e G. A. SIMON. 2000. Estatística Aplicada - Economia Administração e Contabilidade, 9. ${ }^{a}$ Edição. Porto Alegre: Bookman.

GONÇALVES, Cunha. 1914. Comentário ao Código Comercial português, volume I. Lisboa: Empreza Editora J. B.

LEITE, João. Cooperativas de interesse de público em Portugal, texto disponível em http://www.cases.pt/0_content/actividades/doutrina/cooperativas_de interesse_publico_em_portugal.pdf (última consulta em 20 de novembro de 2016).

MEIRA, Deolinda A. 2009. O regime económico das cooperativas no Direito Português: o capital social. Porto: Vida Económica.

MEIRA, Deolinda A. 2015. "Contributos legislativos para a criação de empresas cooperativas: a livre fixação do capital social». CIRIEC-España, Revista Jurídica de Economía Social y Cooperativa, n. ${ }^{\circ} 26:$ 35-37.

MEIRA, Deolinda A. e Ana Maria BANDEIRA. 2010. "A IAS 32 e os novos critérios de contabilização das entradas para o capital social das cooperativas. Uma análise contabilística e jurídica». Revista de Ciências Empresariais e Jurídicas, n. ${ }^{\circ}$ 16: 145-164.

PANIAGUA ZURERA, Manuel. 2005. Las Sociedades Cooperativas. Las Sociedades Mutuas de Seguros y las Mutualidades de Previsión Social. Madrid-Barcelona: Marcial Pons.

PASTOR SEMPERE, María del Carmen. 2002. Los recursos propios en las sociedades cooperativas. Madrid: Editoriales de Derecho Reunidas, SA.

RODRIGUES, Ana Maria Gomes. 2009-2010. «Os novos desafios da Contabilidade para Organizações da Economia Social que aplicam o SNC - As Cooperativas», Revista Cooperativismo e Economia Social, n. ${ }^{\circ}$ 32: 115-140.

STUDY GROUP ON EUROPEAN COOPERATIVE LAW (SGECOL). 2015. Draft Principles of European Cooperative Law (draft PECOL), http://www.euricse. eu/wp-content/uploads/2015/04/PECOL-May-2015.pdf (última consulta em 20 de novembro de 2016). 
TORRES PÉREZ, Francisco José. 2006. Régimen Jurídico de las Aportaciones Sociales en la Sociedad Cooperativa. Navarra: Editorial Thomson Aranzadi.

VARGAS VASSEROT, Carlos. 2007. "La NIC 32 y el capital social cooperativo», REVESCO. Revista de Estudios Cooperativos 91: 120-159.

VARGAS VASSEROT, Carlos. 2011. "Aportaciones exigibles o no exigibles: ésa es la cuestión». CIRIEC-España, Revista Jurídica de Economía Social y Cooperativa 22: 75-119.

VICENT CHULIÁ, Francisco. 1994. Ley General de Cooperativas, Tomo XX, Vol. 3.․ Madrid: Editoriales de Derecho Reunidas, SA.

VIGUERA REVUELTA, Rodrigo. 2015. El derecho de reembolso en las sociedades cooperativas. Valencia: Tirant Lo Blanch. 


\section{Derechos de autor}

El Boletín de la Asociación Internacional de Derecho Cooperativo es una revista de acceso abierto lo que significa que es de libre acceso en su integridad inmediatamente después de la publicación de cada número. Se permite su lectura, la búsqueda, descarga, distribución y reutilización legal en cualquier tipo de soporte sólo para fines no comerciales y según lo previsto por la ley; sin la previa autorización de la Editorial (Universidad de Deusto) o el autor, siempre que la obra original sea debidamente citada (número, año, páginas y DOI si procede) y cualquier cambio en el original esté claramente indicado.

\section{Copyright}

The International Association of Cooperative Law Journal is an Open Access journal which means that it is free for full and immediate access, reading, search, download, distribution, and lawful reuse in any medium only for non-commercial purposes, without prior permission from the Publisher or the author; provided the original work is properly cited and any changes to the original are clearly indicated. 